\title{
Certain aspects of digital development in AIC
}

\author{
Indira Mikitaeva ${ }^{1, *}$, Eldar Malkanduev ${ }^{1}$, Pavel Zhufan ${ }^{2}$ and Saida Shardan ${ }^{3}$ \\ ${ }^{1}$ Kabardino - Balkarian State Agricultural University named after V.M. Kokov, Lenin Avenue, 1V, \\ 360030 Nalchik, Russia \\ ${ }^{2}$ Mendel University in Brno, 1, Zemedelska, 61300, Czech Republic \\ ${ }^{3}$ North Caucasian State Academy, Cherkessk
}

\begin{abstract}
The social and economic development of the territories includes the existence of stable interregional food and commodity linkages, the formation of a food economy, an increase in food resources conducive to the development of the AIC and the entire economic system. Digitalization and the implementation of information technologies ensure high-quality information content of all subdivisions of the AIC, enable optimization of the flow of resources and goods within the complex, leading to facilitate the task of transforming the agro-industrial complex of Russia, further "effective and sustainable agro-industrial production that corresponds to the world level ensuring the country's food security, the saturation of the market with food "[4]. An effective mechanism for the regional innovative economy management is, in our view, the complex establishment of a high-quality information base, the development of information technology networks to transcend traditional technologies. The success in the transition to the modern stage of the digital economy in the AIC prejudges the growing importance of the of the country, its regions and individual industries in the formation of a single information field. The federal policy policy is directed at creation of new information technologies and communication channels throughout Russia and all over the world. The regional policy in the field of information should be based on the interests of the regional users and the general federal interests of a group of industries located in the region. The sectoral policy in the field of information should take into account the interests of one industry, as well as enterprises and organizations within the structure of this industry.
\end{abstract}

\section{Introduction}

The problem of digitalization has become a priority at the current stage and its importance in society is constantly increasing. The latest achievements in informatics, computer science and telecommunications have created a new type of high technology - digital technology. The information economy development, that is primarily information technology (IT) services and advanced information and communication technologies (ICT), have become globalized and have become a defining feature of the country's level of development.

\footnotetext{
${ }^{*}$ Corresponding author: diseconkbgau@mail.ru
} 
The creation of digital technologies is focused on the economic efficiency and sustainability of the country and its regions. The most developed enterprises in the industry regarding information technology can promote synergies in increasing their efficiency mainly by reducing transaction costs in combining into a common information exchange network.

The relevance of the development and implementation of modern information technologies in the agro-industrial complex of Russia is determined by the strategic role and importance of the AIC for the provision the country with agricultural products, raw materials and food.

\section{Materials and Methods}

During the research, such methods as analysis and synthesis were used. The research materials are the works of prominent academic economists from around the world and statistical data.

\section{Results and Discussion}

The study identified that there are challenging tasks of creating information technologies in the sectors of the AIC, which may be summarized as follows: Primarily, there are structural weaknesses in the digital transformation ecosystem, a relatively low level of digital skills, there is no open innovation culture.

The tasks of establishing global information complexes in the sectors of the AIC include:

- to improve federal, sectoral and regional policy in the field of information and to implement modern information technologies;

- to develop information technology networks, information services market and to integrate into the world system of creating new information technologies in the AIC.

Addressing these problems requires AIC staff development in information technologies and telecommunications, in order to implement new information technologies, and to develop consulting and expert services networks. The development of a new information culture is facilitated by the higher education system, engaged in providing the intellectual potential in the field of information, network technologies for the sectors of the AIC. According to Evgenii Sandomirskii, EPAM Systems Senior Business Development Manager, "Today people have become the main asset, and information has become the main resource. It is necessary to equip people with relevant information, to invest in their skills, talents and to provide them with convenient tools for work"[3]. E. Sandomirskii pointed to the McKinsey \& Company research, whereby three factors influence the success of a company's digital transformation:

- ease of access to information for all employees in combination with transparent communications;

- independent use of self-service services by employees;

- close cooperation among various units.

The development of training centers that focus on training both administrators and users is required to ensure that any user could master the office suite in short time. Nowadays, not only technical support is important, but also assistance with implementation. The implementation projects, assisting administrators during implementations, from our point of view, specifically requires particular attention.

It should be mentioned that at the current stage, certain successes have been achieved in terms of creating information management systems related to the qualitatively new level of 
application software development. Software, as an independent and basic use of information technologies in the field of management systems for AIC enterprises, organizations and sectors, covers almost all management fields.

But how to switch to new software so that the effectiveness of the organization does not fall, but grows? Concerns over the inconvenience and unfamiliarity of work are justified. Since there are often difficulties related to established habits of using office applications, on format compatibility. Issues concerning the compatibility with other application software (EDM, BPM, GIS, etc.), enabling the product to be seamlessly implemented into the automated organization's business processes tended to be determined already at the testing stage. Although some of the issues are removed during the initial acquaintance with the product, a more detailed study of the software product requires improvement in the qualifications in authorized training centers.

The foregoing emphasizes the complexity and at the same time the relevance of the tasks for both the users of the programs and their developers.

To make significant improvements in this area, the Russian Government promotes the implementation of disruptive innovation by investing in national broadband infrastructure. In the era of implementation of import substitution programs, the state declared a quest for import substitution of office products, developed recommendations on the transition of public authorities at various levels and state-owned companies to the preferential use of indigenous software, including indigenous office software. The recommendations lists the measures to be included in the transition schedule, formulated indicators of the transition efficiency, the share of national office suites to the total use of office software to be achieved.

Projects for the program implementation are actively developing, the automation loops are expanding, progressively covering new functionality, including those related to the robotization of typical operations,to the use of artificial intelligence algorithms, and multidimensional data visualization (Fig. 1).

\section{Dynamics of the Russian EDMS/ECM market, billion rubles}

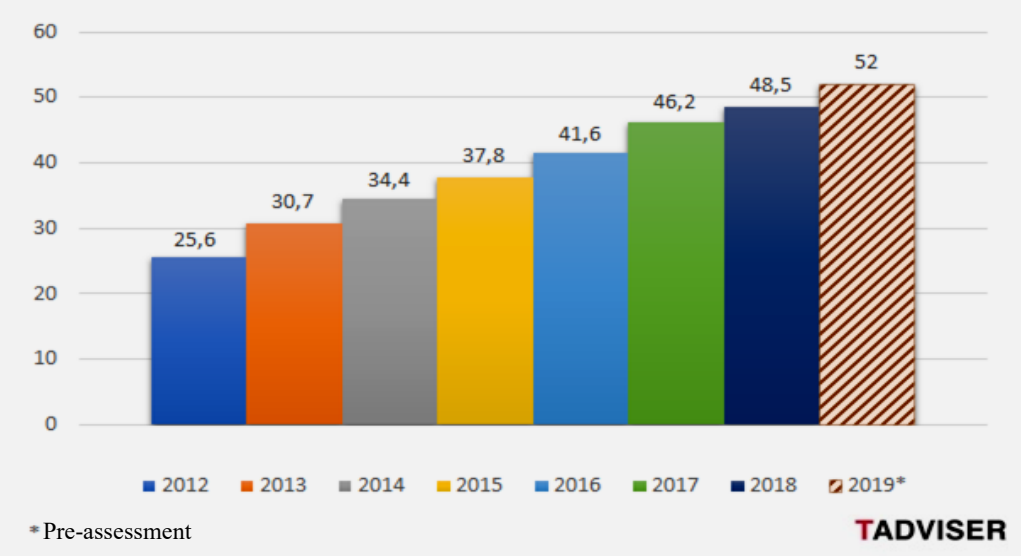

Fig. 1. Dynamics of the Russian EDMS market, billion rubles

*Compiled from TAdviser data

According to TAdviser, the market growth was about 5\%, amounting to 48.5 billion rubles. At the end of 2018, the indicators of a number of major players shrank. According to the preliminary results of 2019 , the market growth rate of $7 \%$ is expected, nevertheless its volume will not exceed 52 billion rubles [7]. 
The results of 2019 demonstrated that, despite all the government's initiatives, it is too early to talk about mass import substitution. However, the first signs of this process have already emerged. At the end of 2019, the Ministry of Digital Development, Communications and Mass Media carried out central procurement of Russian office programs and antiviruses for a total amount of over 1 billion rubles.

This situation makes actual the position of A. N. Bogatyrev, who stated: "The technological revolution is gradually turning into an intellectual and informational one. Information becomes not only a subject of communication, but also a profitable commodity, certainly, an effective contemporary means of organization and management of social production ... and the social and economic development of society as a whole"[8]. It can be seen that the significance of informatization in all sectors of the economy is constantly growing.

Regarding the agricultural sector, the timely and high-quality spread of digital technologies in organizations and enterprises of the AIC, considering the large extent of the territory of Russia, is economically profitable. The system of information flows, providing high-quality informativity of all sectors of the AIC, makes it possible to optimize the flows of resources and goods inside the complex and, consequently, reinforces the effectiveness of market mechanisms in the reproduction process.

The use of digital systems in the industries of the AIC is very promising due to the following features:

- a wide variety of production and processing of raw materials;

- a significant number of technological processes, many of which are energy- and material-intensive;

- the seasonal nature of the work;

- a large proportion of personnel employed directly in the production of products.

As a consequence of the above features, it is very difficult to analyze the economic and financial activities of organizations, which accentuates the need to use information technologies to obtain a set of information on which it is possible not only to reduce losses in production significantly, but also to improve the use of production facilities and increase the efficiency of production and sales.

The fundamental importance of increasing production and promoting agricultural products is also due to the leading role in the maintenance of the food security of the country and its regions. Considering the strategic and systemic role of the AIC, extensive use of digitalization can significantly enhance the competitiveness of agricultural products and the investment attractiveness of the industry, enhance the linkages "between the key stakeholders of the digital ecosystem, including the public and private sectors, civil society and the scientific and educational community" [9].

Today, a balanced growth of the agro-industrial complex of Russia is impossible out of the information field. The agro-industrial complex of the Kabardino-Balkarian Republic is no exception, the growth of which is associated with the provision of high-quality informativity in all areas and sectors, and specialists - with access to regional, national or international telecommunication networks.

The interrelationship of various production structures through the establishment of stable vertical and horizontal linkages, the use of the potential and principles of partnership between the state and private business, modern information technologies, innovative approaches will allow the agro-industrial complex to reach a competitive level of production development [6].

The information support system has a significant impact on the choice of potential areas of investment by investors, since new capabilities of information and computer technologies provide access to the study, for example, of an investment passport of a particular municipal district. 
We have investigated the official website of the Maysky municipal district of the Kabardino-Balkarian Republic, which provides comprehensive information on both the National projects, Federal and regional programs implemented in the territory, and indicators on the state of the economy and social sphere of the municipality (Fig. 2). The section "Investment activity" presents the investment policy of the municipal district, which is to create the most attractive conditions for investment in the development of local production and social infrastructure. The same section contains a list of local laws and secondary legislation governing business and investment activities, the existing forms of their municipal support: The program of social and economic development of the Maysky municipal district for the period 2016-2020, the Municipal program "Development and support of small and medium-sized enterprises in the Maysky municipal district of the Kabardino-Balkarian Republic for the period 2016-2020", the Municipal program "Development of agriculture and regulation of markets for agricultural products, raw materials and food for the period 2013-2020 in the Maysky municipal district", On the support of small and medium-sized enterprises, On the Investment and Entrepreneurship Board to the head of the local administration of the Maysky municipal district and others.

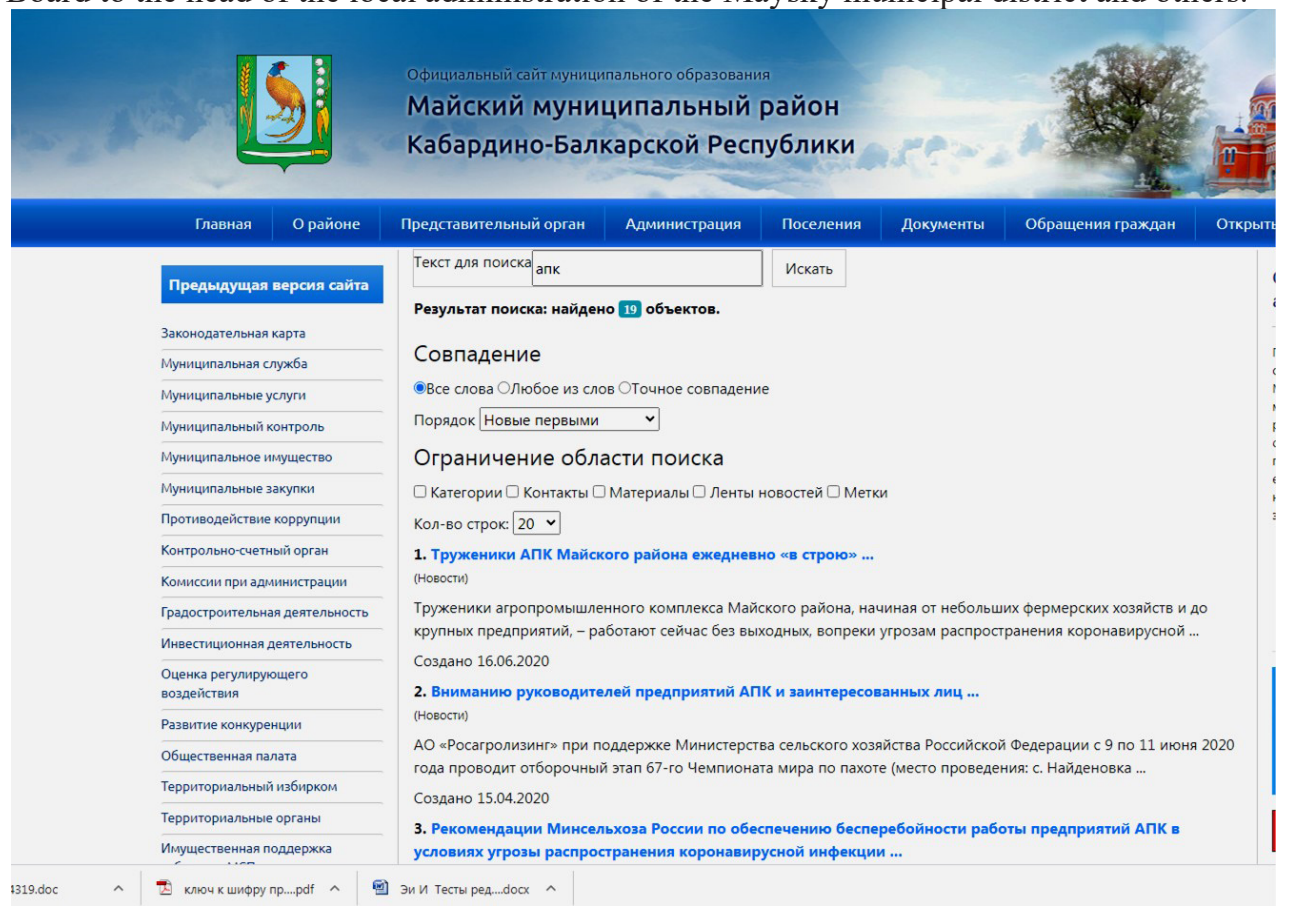

Fig. 2. Fragment of the municipality official website

The list of priority areas for investment in the Maysky municipal district includes: agriculture, processing industry, mechanical engineering, chemical production[5]. A register of investment sites, free and for possible use in the implementation of investment projects in the Municipal District is presented.

To improve the awareness of business entities and consumers of goods, works, services, the section "Promotion of Competition" provides information on the state of competition and activities to promote the development of competition.

On the official website and on the Internet portal about investment activities in the constituent entity of the Russian Federation, in a separate section, a publication of interest on measures and infrastructure to support small and medium-sized enterprises (including a separate subsection for agricultural producers) can be found. Publications are structured by 
the development priorities of the constituent entity of the Russian Federation and types of activities, indicating the procedure for obtaining mentioned support (including in the form of a scheme) and indicators of the efficiency of the regional program within which this activity is carried out. The amount and detail of information disclosure should reflect the coherence of the investment programs of natural monopolists with the territorial development plans of the entity.

The specified example demonstrates the interest in creating a unified information space for receiving a set of information for the further growth and development of the region.

Due to the digital transformation based on a set of technologies, big data, the Internet of Things, cloud computing, artificial intelligence and a number of others, the most important condition for the dynamic growth of economic sectors of the regions and the country as a whole will be created. In the fair view of Shardan S.K., the involvement of breakthrough technologies has become a vital necessity. An effective mechanism for managing the regional innovative economy according to the author is "the integrated implementation of such functions as the formation of an information base about management objects ..."[2]. Let us only clarify that the increase in cloud services, digital platform significantly reduces the time period of the innovation cycle and thereby causes an increase in the rate of renewal of innovative products and technologies.

\section{Conclusions}

The market environment, in the context of the rapid development of information technology, places on each participant high demands associated with the increasing amount of information and the increasingly complex system of relationships between market participants and a wide range of stakeholders. In order to meet the requirements, correctly focus and find the right solutions, market participants and business entities need to move beyond traditional technologies [1].

As a result of the study, we have identified some aspects that determine the success in the transition to the modern stage of the digital economy in the AIC.

1. The federal policy aimed at creating a unified information space is highly relevant and timely. It relates to the intensified development of education in the field of informatics, retraining and advanced training of specialists of all levels, the development of scientific research in the field of creating new information technologies and communication channels all over Russia and all over the world.

2. The regional policy in the field of information should be based on the interests of the regional users and the general federal interests of a group of industries located in the region. The regional aspect of digitalization includes the stable interregional food and raw materials linkages, the creation of a food base, and the increase in food resources conducive to development of the AIC and the entire economic system.

In creating a single information space, it is important to take into account regional differences. Each region develops its own strategy for the transition to import substitution, its typical workplace, which includes, besides an office suite, an operating system, an office, e-mail, antivirus, an electronic document management system. In addition, in each region there are government information systems (GIS) which solve specialized problems. For example, they are variable in the timing and sequence of stages of a transition project. One first chooses a certain operating system, installs it, then transfers all GIS to it, and only then purchases an office suite, mail and antivirus, that is, application systems. The second approach is slightly different: it implies to install something that does not depend on the choice of the operating system first. For example, "R7-Office", running on all domestic operating systems. Such an installation, for the record, is technologically safe, since it does not strategically affect the possibility of the subsequent choice of an operating system. 
3. The sectoral policy in the field of informatization should proceed from the interests of one sector, taking into account the development of the regional and federal levels of informatization. Being in general relationships with each other, the interests of enterprises and organizations that are part of the structure of this industry are resolved at the sectoral level.

4. Finally, each agricultural organization or processing enterprise, as the primary unit of informatization, solves the problem of implementing new information technologies and telecommunications, comparing its interests with the policy of the industry, region, state.

This approach will obviously result in the provision of the social and economic development of the territories and the implementation of the main strategic national priorities.

These are the main provisions of the trends of digitalization and the implementation of information technologies that contribute to facilitate the task of transforming an important sphere of the economy - the agro-industrial complex of Russia.

The article was prepared with the financial support of the Russian Foundation for Basic Research, project No. 20-010-00838A

\section{References}

1. A. I. Altukhov, The Economic Problems Of Innovative Development Of Grain Subcomplex In Russia (2015)

2. Saida K. Shardan, Nazgul B. Davletbayeva, Svetlana S. Morozkina, Deschi Sh. Musostova, Anastasia V. Sharopatova, Journal of interdisciplinary research, http://www.magnanimitas.cz/

3. Digital transformation day 2020, https://www.tadviser.ru/index.php

4. Indira R. Mikitaeva, Marina T. Tekueva, Mikhail Kh. Balkizov, Tanzila H. Sozayeva, Journal of Organizational Behavior Research, 3(2), 192 (2018)

5. Investment passport of the Maysky municipal district, https://mayadmin-kbr.ru/

6. National models of economic systems: collective monograph (2019)

7. Russian EDMS/ECM market, https://www.tadviser.ru/

8. A. N. Bogatyrev, V. A. Panfilov, V. I. Tuzhilkin et al., System of scientific and engineering support of food and processing industries of agriculture in Russia (1995)

9. T. H. Sozaeva, A. Yu. Pshigosheva, S.A. Gurfova, I. R. Mikitaeva, Agrarian territories in the context of the formation of a digital economy: problems and prospects (2020) 